\title{
Negotiating between the Constant and the Changing: Balancing Acts in the Training of Writing Teachers
}

\author{
Heping Zhao \\ California State University, Fullerton \\ hzhao@Fullerton.Edu
}

Abstract

\begin{abstract}
TA training is an important component of any rhetoric/composition program in American universities. As a faculty member in the Department of English, Comparative Literature, and Linguistics with a specialty in classical oratory and comparative rhetoric, I have been training TAs for over a decade as a significant portion of my teaching assignment. In my presentation, I would like to discuss the major factors that affect the quality of the TA training program and ways to balance these factors to maximize the learning experience for the TAs. TAs, short for "teaching assistants" or "teaching associates," are graduate students in English who are assigned to teach a writing class or two, usually of beginning college level. It is essential that these graduate students be provided with detailed hands-on training both in theory and in practice every step of the way in order for them to feel confident and comfortable in the classroom. My role as their teacher and supervising instructor is to provide them with fundamental training, laying a solid foundation for them to grow professionally. As I see it, four major factors interact in the TA training process: the available theory, the institutional and academic expectations, the class of student writers they each teach, and the TAs themselves as a team. Some of these factors are relatively constant; others are fluid and always changing. They often present fresh challenges when they interact in the writing classroom. I would like to explore how these factors act upon each other and complement each other as I try to create an environment in which the TAs feel encouraged to learn and experiment on their own with a minimal amount of guidance. I will argue that, based on my years of experience and on the reflections by the TAs themselves, it is of critical importance that the focus be placed on the balancing of the four factors in an individualized approach for TA training.
\end{abstract}

Keywords: rhetoric, TAs, composition, training program.

\section{Introduction}

One day thirty years ago when I first switched from linguistics to rhetoric and composition as a graduate student at Purdue University, an older student gave me a very unusual introduction to the TA program that I will never forget. He did so with a simple analogy. "Teaching your own writing class for the first time," he said, "was like going on your first date, very exciting, but absolutely petrifying." A few years later, I saw this same analogy, given by the same person of course, but in print this time, and applied to a slightly different context: the writing center:

Six years ago when I began working as a peer tutor, I felt pretty awkward; in fact my first tutorials were as frightening as my first dates. I didn't know what to say_but I was scared to death of silence-and I can remember so well not knowing what to do with my hands.

Like that first date, no matter how much the big kids told me about what to do on a date, l'd never seen one. (Adams, 1987)

Little did I know then that, a dozen years later, I would be sitting at my desk, musing at my own destiny in helping new graduate instructors of college composition to overcome their fear, almost literally holding their hands to calm them down as they walk awkwardly into the classroom for the first time, filled with excitement, nervousness, anxiety, and uncertainty all at the same time. As coordinator of a sizeable teaching associate program—or TA program for short-in a large public university in California for the last ten years or so, I am charged with the responsibility of recruiting new TAs from second- 
year English graduate students, enroll them in a year-long training course with a total of four credit units, and supervising them every step of the way as they each teach one section of English 101: Beginning College Writing, for two consecutive semesters.

Generations of researchers and composition practitioners agree that writing is a social act (Bruffee, 1984; Trimber, 1989; Bizzell, 1994; Lu, 1994, Higgins, Long \& Flower, 2006). Like writing, the teaching of writing, particularly the training of teachers of composition itself, is a social act, too. From the time I was a graduate student decades ago on the receiving end of training to the present time when I am the one in charge of offering training courses to graduate students and supervising their teaching on a daily basis, there has always been a strong presence of togetherness, one not just of people, but of entire community or institution in which the art of teaching composition is learned and taught. The learning and teaching, however, are by no means mono-directional. The teacher often times can be the student just as the student can be the teacher. Learning and teaching are thus multi-dimensional interactions. From my years' of working in the capacity of a TA supervising instructor, I can identify four major factors that interact with each other in this process: the available body of theory, the institutional and academic expectations, the TAs themselves as a team, and the class of student writers they each teach (See below). Some of these factors are constant; others are fluid and often changing. They always present fresh challenges when they interact in the writing classroom. I would like to explore how these factors act upon each other and complement each other as I try to create an environment in which the TAs feel encouraged to learn and experiment on their own with a minimal amount of guidance. I will argue that, based on my years of experience and on the reflections by the TAs themselves, it is of critical importance that the focus be placed on the balancing of the four factors in an individualized approach for TA training.

\section{Student Writers}

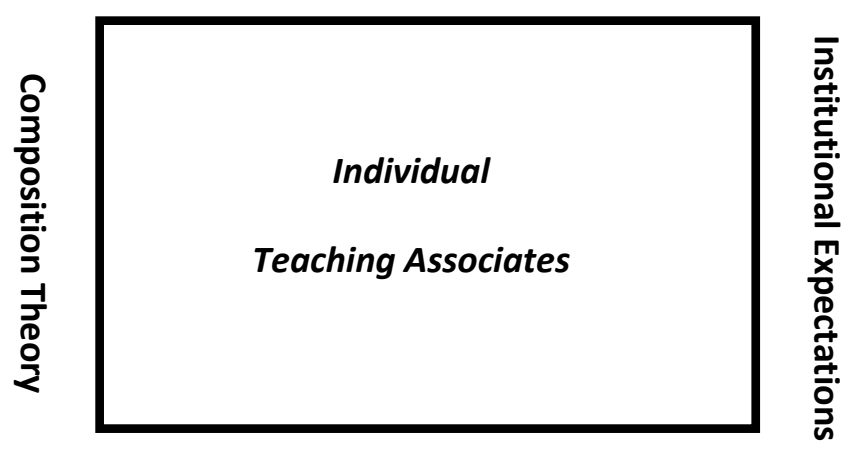

\section{The TA Team}

\section{Institutional Expectations}

University students all across America are required to take writing classes. Such classes are divided into lower-division entry level writing and upper-division discipline-specific writing. At my school, students regardless of their majors must take English 101, Beginning College Writing, upon entering the university. As one of the core General Education requirements, English 101 is designed to help students explore such basic elements of writing as aims and modes of the written discourse, lines of effective reasoning in persuasion, stylistic variations in different rhetorical and academic contexts, and roles of audience in the act of written communication. Students must earn a minimal grade of $C$ to pass the course. Typically, the course incoperates a good deal of reading that's meant to help facilitate in-class discussions and to enhance students' critical thinking skills necessary for strong writing. In fact such skills are essential in organizing materials, structuring arguments, and devoloping the writers' voices. While grammar, punctuation, and spelling are considered superficial and given not as much attention, they will be addressed if they start to affect readability. In general, students in English 101 are expected to achieve the following outcomes as laid out in the English Department Guidelines (2000): 
English $10 \mathrm{I}$ has a number of outcomes which we expect our students to achieve by the end of the course. Students should

- Write well-supported, well-developed essays which show a clear purpose;

- Respond to the needs of varied audiences;

- Understand that all college writing demonstrates reflection and analysis but different kinds of writing require particular rhetorical approaches;

- Use writing and reading for critical thinking, which may include learning to synthesize, paraphrase, and quote from sources;

- $\quad$ Be able to use the conventions and syntax of Standard Written English;

- Compose 7-10 prose pieces, which may include revisions and in-class, timed essays.

These desired "outcomes" are what I will take as institutional expectations. Because they generally remain unchanged or un-revised for a long period of time (the above was last revised in 2000), I will consider them to be a constant factor. I do so with complete awareness that what I call "constant" here or "fluid" later can at best be relatively so. From a historical perspective, all things change and nothing is absolutely constant; conversely, the fluidity of anything can be seen as constant because it goes through changes all the time, which is the basis for constancy.

Given the rigor of the course and the high expectations from the department on the one hand and the typical freshmen's umpreparedness for challenges on the other, many students find themselves in the unpleasant situation of having to retake the course. Making these course objectives absolutely clear to the new TAs and helping them achieve these objectives in their respective classes can therefore be an essential part of the training program.

\section{Rhetoric/Composition Theory}

Another constant factor is theory. The establishment of rhetoric/composition studies as a legitimate and well-respected academic discipline roughly in the second half of last century and the ever growing expansion of such programs across American campuses have produced a sizeable body of theory on the teaching of writing. Although the TA program is primarily a hands-on practicum, it must ground itself in a solid theoretical foundation. Most of the TAs, in spite of their brilliant performance in the graduate classes they take, have had little exposure to the field of rhetoric and composition. While in a typical TA class of 12 to 15 , there might be only two or three who want to pursue a career in teaching writing at the college level, the majority of them, however, join the program just to cultivate a new dimension of their marketability, their main interest remaining in the study of literature or other areas of emphases in English, comparative literature, or linguistics. To be fair, almost all of the TAs have worked in the university writing center or the learning center since such experience is prerequisite for applying to the program; that experience alone, however, can in no way compensate their lack of knowledge on theory. It is therefore imperative that reading and discussion of the current theory be an integral part of the training.

To that end, collections of essays on the current thinking by some of the best known researchers in the field are assigned throughout the year, although most of the theoritical explorations are carried out in the first semester. Weekly journals on these readings and subsequent in-class discussions reinforce the learning of the theoretical component of this training course. Time constraint necessitates the limit of reading selections, with most of them focusing on the classroom effectiveness in today's multi-cultural, multi-lingual setting as typified by our campus. Currently, The St. Martin's guide to teaching writing by Cheryl Glenn and Melissa Goldthwaite (2014), Assigning, responding, evaluating: A writing teacher's guide by Edward White (2007), and First time up by Brock Dethier (2005) make up the list of required textbooks. Supplemental and recommended texts include Cross-talk in comp Theory edited by Victor Villanueva and Kristin L. Arola (2011) and Relations, Locations, Positions: Composition theory for writing teachers by Peter Vanderburg, Sue Hum, and Jennifer Clary-Lemon (2006). 


\section{Student Writers in English 101}

Academic standards and theoretical framework aside, what really matters in the training of those new TAs is how they actually teach their students in the writing classroom. As individuals, students in any class are necessarily different from one another, each with unique abilities and personalities. They are thus fluid and changing, in contrast to the aforementioned factors of institutional expectations and composition theory, which are relatively constant. Seen collectively, though, the entry level student writers in English 101: Beginning College Writing, do share certain common characteristics that are readily observable. The English Department's Course Guidelines (2000) describe English 101 students in the following way:

[Entry-level writing] students at CSUF make up a diverse ... community. They come from a variety of learning environments, including American High schools and overseas schools, and often use English as a second or third language, or as a second dialect. This course is therefore designed to assist students with a wide variety of writing skills and to take into account the linguistic, cultural, and social situations from which our students come.

As it is known throughout the world, Southern California, where my university is located, is perhaps one of the most diverse cosmopolitan areas in America in terms of the number of ethnic origins people represent, languages and dialects they speak, cultural practices and customary habits they embrace, and economic stratifications they fall under. Our students are products of this rich diversity, one that can make the writing class infinitely interesting and vibrant, but can also create numerous challenges. Writing, being at an advanced stage of cognitive development and linguistic competence, requires a solid all-round command of knowledge, not only of the English language, but also of culture, history, society, and so on. It is therefore impossible for students in any English 101 class to be equally prepared academically or to be on the same footing. In spite of the superficial scores on their English Placement Test administered throughout the entire 23-campus California State University system and taken by every single freshman before they enroll in any of these campuses, students who are identified as "college-ready" and thereby routed into the classroom of English 101 always differ broadly in terms of their writing ability, critical thinking skills, reading speed and comprehension, and level of linguistic fluency. To help them reach the goals set out for them in the aforementioned English Department Guidelines, necessary measures must be taken to make each and every student:

- Understand that it usually takes multiple drafts to create and complete a successful text,

- Develop flexible strategies for generating, revising, editing, and proof-reading,

- Become aware that writing is an open process which permits writers to use later invention and re-thinking to revise their work,

- Understand the collaborative and social aspect of writing processes,

- Learn to critique their own and others' works,

- Use a variety of technologies to address a range of audiences.

These measures constitute the various segments or aspects of the writing process. They may overlap, they may intersect, or they may operate independently of each other. Some of them may feature more prominently in some types of writing than in others. Taken together, though, they form the core elements that English 101 and other writing classes must address. It is of paramount importance that all these elements be highlighted in the TA training course agenda. They must be emphasized alongside course objectives and desired outcomes throughout the year-long program.

\section{The Teaching Associates as a Team}

Among the numerous ways of learning, the most effective may very well be that of peer influence. We all know the value of partnership, of collaboration, of teamwork. Working together, we make wonders. TA training is no exception. As another fluid dimension in the overall framework of TA training, these teaching associates each bring to the program a vast array of experiences and expectations. As individuals they differ in personality, in attitudes, in work habits and so forth. As a team, though, they share three things in common: first, they are all new to the art of teaching composition; second, they are all in the program to learn this art well enough to become effective teachers; and third, they are all determined to excel in this learning process. 
These commonalities keep them together. They bond. They learn from each other. Sharing comes very naturally to them. I don't even have to tell them to share. They simply do all the sharing on their own. They share ideas of what works and what doesn't; they share tips of effective lesson plans or activities; they share discussion topics or even essays prompts. And they share stories and observations of their students, of classes, and of me sometimes. They do all this sharing not only during the weekly class meetings, but also in their offices, in the hallway, in their Facebook chatroom, or wherever they happen to bump into each other. Just as Dethier puts it in his First time up (2005),

Camaraderie may be the most alluring and addicting aspect of the comp teacher's job. An unusual and powerful bond develops when you wander, punchy and bleary, into your neighbor's office after you've both survived a day of three classes or twenty-seven conferences. Or when you suggest just the right activity when your officemate rushes in, frantic for ideas, ten minutes before class. Or when you spend two hours and $\$ 10$ of beer money grousing about the student who won't shut up or the class that won't talk. (5)

The best part of this bonding is that is simply happens. It goes with the professional culture. I as the program's coordinating or supervising instructor really don't have to do anything to make them bond. They do it on their own. All I have to do is to provide them with the space for sharing and channel their conversation in such a way that each and every TA can benefit from it. I make sure that they have all the time they need during each class meeting to let other TAs know what has transpired in the week before, what they plan to try in the week ahead, what problems they have run into and how they have dealt with them. Other TAs are always invited to help out if anyone of them has an unusual situation or a difficult issue. In addition, I give them assignments that require a great deal of teamwork. For instance, they have to create group presentations on topics that they share an interest in. Or they have to observe each other and report to the class the strengths they have seen during the observation and suggestions for improvement. I encourage them to borrow ideason class activities, on essay prompts, on group exercises or any other kind. There should be no limit in what they want to share. After all, as Dethier (2005) advises his readers who aspire to the profession of teaching writing, "As a new composition teacher, you need to get used to borrowing, whether from veterans like me, founding fathers like Murray, or your officemate whose class ends just before yours begins. If you think you are going to do everything your own way, not follow anyone's footsteps, you'll blow fuses before you turn in your first set of grades. Teaching composition is, and as far as I can tell always has been, a cooperative venture" (1).

So the sharing continues. Each year's TAs carry the tradition onto the next. They freely borrow from others and gladly let others borrow from them. In fact, this sharing not only happens within each group, it often times is passed on in the form of self-compiled collections of ideas, tips, lesson plans, reflections, textbook selections and evaluation, teaching philosophy statements and so on. The photo below shows two such collections, both titled Pupil perhaps to suggest their humble humility as student teachers, one by the class of 2010 and the other by that of 2014, all in the spirit of sharing.

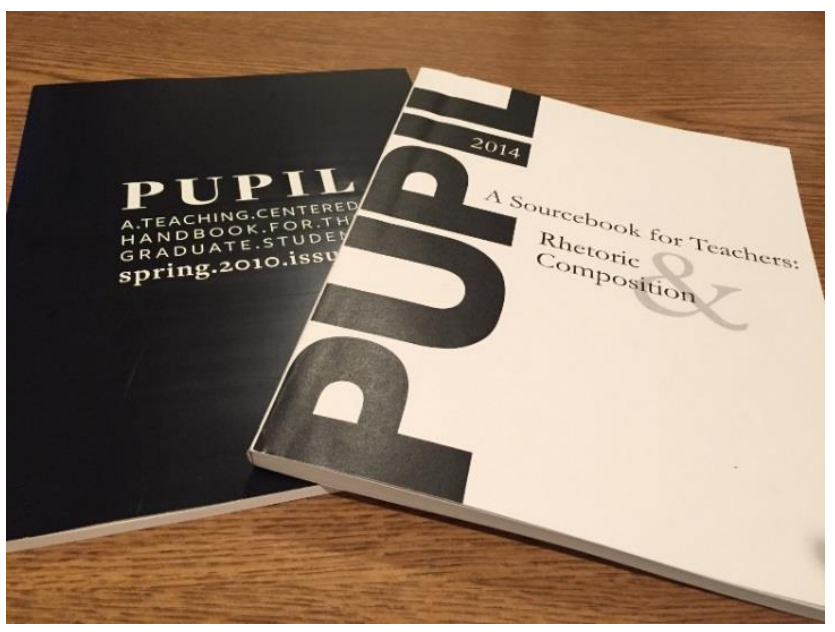




\section{Conclusion}

At the end of each academic year when the teaching associates are ready to graduate and be on their own, I always ask them to write a reflective essay about their experience in the program, what they learned and what they had expected to learn but didn't, and what changes they want to see in order to make it better for future TAs. As always, I give them this assignment with minimal instructions and very little structure in order to encourage them to write freely. Their reflections always vary in length. Some write several pages, others only a paragraph or two. Their comments and suggestions likewise differ, although they are always well-meaning and constructive. Whatever the differences, these reflections always fall within the four areas I have discussed, plus a few words about me as their cheer leader of a supervising instructor.

I feel cheesy to talk about what seems so obvious. After all, anyone can see that a training program such as ours inevitably involves these four aspects. What I wish to emphasize here is that beyond the obvious on the surface, each one of those four areas has many details that can interact differently to the other three, resulting in very diverse outcomes at times. To me, with my role both seemingly at the center — am the program coordinator after all —but actually on the side since I really do not teach English 101 with the TAs, meaningful training takes place only when I adopt an individualized approach, one in which I work with each TA according to his or her strengths and needs. And there is no other way to identify their strengths and needs except in the context of interactivity. The TAs and I work together to determine where their strengths lie and where they need to improve. I observe them as they interact with the theories we read, as they learn to understand and implement the institutional guidelines for the tasks on hand, and as they conduct their classes and work with their students. We talk, discuss, discover problems, solve them, and reflect on each interaction to determine what's done well and what needs more work. Throughout the whole process, I make sure that every TA knows that teaching composition is not just a job--you finish it and you are done. Nor is it a science where there is a correct answer to every question. Teaching composition is an art at which one can always get better, but there is never going to be a best way to teach. As long as the four factors discussed here are present, they will interact differently each and every time. And the best way to handle each one of such moments will always be determined by how they interact.

\section{References}

[1] Adams, R., Child, R., Harris, M., \& Henriott K. (1987). Training teachers for the writing lab: A multidimensional perspective. Writing Center Journal, 7(2), 3-19.

[2] Bizzell, P. (1994). "Contact zone" and English studies. College English, 56(2), 163-169.

[3] Bruffee, K. A. (1984). Collaborative learning and the conversation of mankind. College English, 46(7), 635-652.

[4] Composition Committee (2000) "Course guidelines: Beginning College Writing - English 101." Department of English, California State University, Fullerton.

[5] Dethier, B. (2005). First time up: An insider's guide to new composition instructors. Logan, Utah: 2005.

[6] Glenn, C. \& Goldthwaite, M. A. (2014). The St. Martin's guide to teaching writing (7 $7^{\text {th }}$ ed.). Boston: Bedford/St. Martin's.

[7] Higgins, L., Long, E., \& Flower, L. (2006). Community literacy: A rhetorical model for personal and public inquiry. Community Literacy Journal, 1(1), 9-43.

[8] King, E. et al. (Eds.). (2014). Pupil 2014: A sourcebook for Teachers of rhetoric and composition. Fullerton, California: CSUF.

[9] Lu, M. (1994). Professing multiculturalism: The politics of style in the contact zone. College Composition and Communication. 45(4), 442-458.

[10] Trimber, J. (1989). Consensus and difference in collaborative learning. College English, 51(6), 602-616. 
[11] Vanderburg, P., Hum, S., \& Clary-Lemon, J. (2006) Relations, locations, positions: Composition theory for writing teachers. Urbana, Illinois: NCTE.

[12] Villanueva, V. \& Arola, K. L. (2011). Cross-talk in comp theory: A reader ( $3^{\text {rd }}$ ed.). Urbana, Illinois: NCTE.

[13] Warfe, S. et al. (Eds.). (2010). Pupil: A teacher-centered handbook for the graduate student. Fullerton, California: CSUF.

[14] White, E. M. (2007). Assigning, responding, evaluating: A writing teacher's guide (4 $4^{\text {th }}$ ed.). Boston: Bedford/St. Martin's. 